\title{
Factors Associated with Stunting among 24-35-Month-Old Kalinga Indigenous Children in Pinukpuk, Kalinga, Philippines: A Case-Control Study
}

\author{
Marites B. Piniliw ${ }^{1}$, Leila S. Africa ${ }^{1 *}$, Jaidee P. Agne ${ }^{2}$ \\ ${ }^{1}$ Institute of Human Nutrition and Food, College of Human Ecology, University of the Philippines, \\ Los Baños, Laguna 4031, Philippines \\ ${ }^{2}$ Science Education Institute, Department of Science and Technology, DOST Compound, Taguig, \\ Metro Manila 1631, Philippines
}

\begin{abstract}
The study identified the risk factors associated with stunting among 24-35 months indigenous children in Pinukpuk, Kalinga using case control design; 174 children (87 cases and 87 controls) were randomly selected and information were collected through interview and anthropometric measurements. Odds ratio and $95 \%$ confidence interval were used to measure association. Low birth weight, child drinking brewed or commercial coffee, no nutrient supplement intake since birth, and incomplete immunization were child risk factors of stunting. Exclusive breastfeeding from 0-6 months and weaning at $>12$ months have protective effect. Antenatal visits $<4$ times, father's height $<5$ feet, parent's education below secondary level were parental risk factors. Nuclear household and size of less than five members have protective effect against stunting. Having food restrictions among lactating mothers was cultural risk factors. Mothers' insufficient knowledge on exclusive breastfeeding, frequency of and proper way of breastfeeding, continuance of breastfeeding beyond 6 months, benefit of exclusive breastfeeding for six months to mothers and low self-confidence in preparing complementary food were all associated with stunting. Mother's positive attitude on benefits of frequent feeding was found to have protective effect against stunting. Thus, these family factors could be used when designing an action plan to address the problem of stunting among the indigenous Kalinga children.
\end{abstract}

Keywords: case-control, family factors, stunting

\section{INTRODUCTION}

Stunting remains a global issue, recent 2018 statistics from the World Health Organization showed that $22 \%$ or 149 million children under 5 years old are stunted. While the number has decreased from 2013 with 165 million or $25 \%$, the number is still quite alarming particularly for the low- and middle-income countries (Black et al. 2013). Stunting is defined as having Heightfor-Age Z-score (HAZ) that is less than two negative standard deviations below the age-sex median for a well-nourished reference population. Children affected with stunting have an increased risk of dying and suffering from other adverse consequences throughout life (UNICEF 2015) and is one of the leading causes of the global burden of diseases in childhood and $80 \%$ of this burden is in developing countries (Save The Children 2012). Several studies showed similar results that stunting before the age of two predicted poorer cognitive development and poor educational outcome in later childhood and has significant educational and economic consequences at the individual, household, and community level (Adair et al. 2013; Black et al. 2013; Martorell et al. 2010). Poor socioeconomic conditions and an increased risk of frequent and adverse conditions such as illness and inappropriate feeding practices may give rise to this high level of stunting. Stunting is noticeably high among indigenous people and, in rural communities. The probability of stunting and underweight among indigenous children is almost three times higher than nonindigenous children; the prevalence is highest among those in the Northern Region and South America (Horta et al. 2013; Tanner et al. 2014). In the Philippines, stunting is a public health problem. Results of the National Nutrition Survey showed that the prevalence of stunting among $0-59$ months children is $30 \%$. The country ranked number 9 in terms of number of stunted

\footnotetext{
"Corresponding Author: tel: +639175042768, email: 1safrica@up.edu.ph

(Received 08-12-2020; Accepted 28-06-2021; Published 29-07-2021)
} 
children over 200 countries all over the world (UNICEF 2015). Stunting prevalence in the country among less than 5 years old was highest among the poorest wealth quintile and in rural communities (FNRI-DOST 2015). The Cordillera Administrative Region (CAR), where most of its populations are indigenous people has a $32 \%$ and $37 \%$ prevalence of stunting among under five children in the year 2013 and 2015 NNS, respectively. Children over the age of 24 months have a significantly higher risk of stunting and the likelihood of being stunted was highest for age groups $24-35$ months, followed by $36-47$ months and 48-60 months (Habimana \& Biracyaza 2019). In Kalinga province, a landlocked and culturerich province in the Philippines situated within the Cordillera Administrative Region in Luzon, the prevalence of stunting among children under five is $34 \%$ and $35 \%$ based on the NNS survey in year 2013 and 2015, respectively. If this increasing prevalence of stunting would not be addressed in the early years of life, stunted children would be at risk of the previously mentioned consequences.

Knowledge and information on the relative risk factors associated with stunting would assist policymakers and stakeholders to come up with appropriate interventions to hopefully eradicate stunting problems among the Kalinga Indigenous People (IP) community. Therefore, this study aimed to determine risk factors associated with stunting among 24-35 months old Kalinga in Pinukpuk, Kalinga.

\section{METHODS}

\section{Design, location, and time}

A retrospective case-control study was conducted in Pinukpuk, Kalinga, Philippines from August to October 2018. The municipality is bounded by the municipality of Balbalan on the west; Conner, Apayao on the north, Tabuk on the south, and the municipality of Rizal and partly by the municipality of Tuao, Cagayan on the east. Agriculture is the main livelihood of the inhabitants in the area. Poultry raising and fishing were supplemental livelihoods of the people in the municipality. The ethical clearance was obtained from Cordillera Regional Health and Research Development Consortium - Ethical Review Committee (CRHDRC-ERC) with CRHDRC No. 2018-01. Furthermore, approval from the National Commission on Indigenous People was sought.

\section{Sampling}

A complete list of 594 children 24-35 months old in Pinukpuk, Kalinga was obtained from the Municipal Nutrition Office. The total number of children eligible for the study was 447; 327 were non-stunted and 120 were stunted. The study covered native Kalinga IP in Pinukpuk, Kalinga. Children and mothers with special health conditions and disability were excluded in the study. In this study, stunting was defined based on the WHO Child Growth Standard. Children with a cut-off score of $<-2$ SD for height-for-age were considered stunted and included in the study.

Sample size was estimated using the following value, confidence level $=95 \%$; relative precision $=50 \%$; case-control ratio $=1: 1 ; \mathrm{OR}=2$. From the sample size that was computed (case $=76$, control $=76$, Total $=152$ ), a $15 \%$ non-response rate was used in the study. The total sample size for both case and control children was 87 . Simple random sampling (draw lots) was used to select participants. The case and control were matched based on sex and age. The control was composed of non-stunted children. However, no other inclusion criteria were observed in choosing the control group.

\section{Data collection}

Prior to collection of data, written consent was obtained from mothers or main caregivers of under five children. The data collection techniques employed were interview and anthropometric measurement of height of children. Height of the child was measured using microtoise. All measuring devices were properly verified. Anthropometric measurement standard of Food and Nutrition Research Institute (FNRI) was adopted to obtain the desired precision and accuracy of height data. Independent variables such as child, parental, household, socioeconomic, community, and cultural characteristics, maternal knowledge, practices, and attitude, and Infant and Young Child Feeding (IYCF) was collected using structured questionnaire via face-to-face interviews with mothers or main caregiver of children between 24-35 months. Child characteristic consisted of sex, type and place of delivery, birth weight, health care, supplementation and immunization. The parental, household, and socioeconomic factors included mother's age of conception, prenatal and antenatal care, parental height, 
educational attainment, employment status, type and size of household, annual income, dwelling status, and appliance and vehicle ownership. The community and cultural factors composed of accessibility to water, water treatment, health access, and food beliefs. Mother's knowledge, attitude, and IYCF practices were also collected. Questions on IYCF questionnaire were adopted from the 2013 Philippines National Demographic and Health Survey (NDHS) and 8th National Nutrition Survey questionnaire which includes exclusivity and duration of breastfeeding, age of weaning and complementary feeding. This questionnaire was pretested to ensure reliability $(\alpha=0.78)$. The data were collected by four Barangay (village) Nutrition Scholars who can speak "Kalinga and Ilokano", the dialects in the locale. They had a one-day training to learn the study objectives, apply proper interview techniques, and do anthropometric measurement. Filled questionnaires were checked for its completeness every after-interview session.

\section{Data analysis}

The data obtained from the questionnaires were encoded, processed, and categorized using Microsoft Excel. Descriptive statistics, frequency distribution in particular were used to compare the characteristics of the households, children, parents, practices, among others in the case and control groups. Odds ratio and $95 \%$ confidence interval was used to measure association of stunting risk factors and measure the strength of the association. Binary Logistic Regression was used to determine odds ratio in this study. Matching sex and age of participant was used to control confounding variables. All analysis was done in SPSS version 16.

\section{RESULTS AND DISCUSSION}

\section{Characteristics of the case and control households \\ Child characteristics. Higher proportion} of the children was females in both cases $(55 \%)$ and controls (55\%). Also, majority of the children in both cases and control were born via normal delivery $(92 \%, 90 \%)$ and were taken to hospitals or clinics when ill $(95,95 \%)$. Also, children delivered at home and with low birth weight were higher among cases $(20 \%, 31 \%)$ than in controls $(15 \%, 11 \%)$. More children in the control group had complete immunization (97\%) and had taken nutrient supplements since birth (92\%) compared to the case group that had more children who undergone medication since birth (72\%). Finally, more than 80 percent of main caregivers in both groups were mothers.

Parental characteristics. In terms of parental factors, ages of mothers upon conception ranged from 12 to 45 years old. Specifically, mothers younger than 18 years old and older than 35 years old upon conception were higher among cases $(33 \%)$ than in controls $(22 \%)$. It is worth noting that almost all the mothers had prenatal check-up in both groups. Mothers who had their prenatal check-up at less than 4 months of pregnancy were higher among controls $(90 \%)$, and mothers who had equal or less than four times antenatal check-up were higher among cases $(51 \%)$. On parental height, mothers and father with height below five feet were higher among cases $(63 \%, 18 \%)$ than in controls $(49 \%$, $5 \%$ ). In terms of education, mothers and fathers who attained below secondary level were higher among cases $(18 \%, 31 \%)$ than in controls $(11 \%$, $28 \%$ ). Meanwhile, in terms of working conditions, there were more working mothers among cases than in controls.

Household characteristics. More than half of the households in the study were nuclear family; it is higher among the cases $(68 \%)$ than controls (53\%). Households with members greater than five were higher in controls (64\%) than in cases $(62 \%)$. Majority of the households has annual per capita income above the annual poverty threshold in CAR. Almost all households owned the dwelling they were occupying; however, $11 \%$ of the case and $8 \%$ of the control households had no electricity.

Socioeconomic characteristics. Majority of the households in the study owned livestock. Households owning land were higher among controls (54\%); whereas, households renting land $(34 \%)$ and landless $(23 \%)$ were higher in cases. Majority $(89 \%)$ of the households in the study owned functioning appliances, higher (91\%) among controls compared to cases $(87 \%)$. More than one third $(38 \%)$ of the households, in both groups, owned transport vehicles; however, fourwheel transport vehicles owned by controls were two times higher (18\%) than cases $(6 \%)$.

Community characteristics. The sources of drinking water of the households in the study 
were mostly dug well (56\%), water from spring $(45 \%)$, and refill (6\%). Majority $(80 \%)$ of the case households applied water treatment to make their water safer to drink. The number of households using water from refilling stations was higher $(8 \%)$ in control than case group $(4 \%)$. There were instances that prevented pregnant mothers to access health services. More respondents in cases $(7 \%)$ mentioned that it was a big problem for them to get permission to go to the doctor for prenatal care compared to control respondents $(1 \%)$; one third $(33 \%)$ of the cases said getting money for medication was a big problem; more than one fifth $(24 \%)$ said that distance to health facility was a big problem, and $8 \%$ said that not wanting to go alone was a problem respectively higher than controls.

Regarding foodaccess, majority of both case and control groups claimed that their food comes from their own produce $(84 \%, 82 \%)$ and nearby store $(94 \%, 92 \%)$. More of the case households $(57 \%)$ were located greater than five kilometers away from the wet market compared to controls (47\%). Households with backyard gardens were higher (83\%) among controls than cases (79\%); most of the produce for both groups were for human consumption $(87 \%, 80 \%)$; and most of them started before the year 2015 (70\%, 72\%).

Cultural characteristics. In terms of cultural belief, more than half of respondents do not believe on food that could cure sickness, and majority (98\%) do not believe that there is food in their community that could cause adverse health effects. For newborns, 12\% of the case respondents believed that vegetable or fruit extract should be given to newborns for cleansing. Regarding food taboo among pregnant and young children, more respondents $(21 \%)$ in control have food taboos compared to cases $(12 \%)$. Respondents in case household believed that stunting is caused by genetics (51\%), malnutrition (32\%), and sickness (3\%). The same causes were identified by respondents in control but more mentioned genetics. There were more respondents in case $(30 \%)$ than in control $(22 \%)$ who had no idea about stunting.

\section{Maternal knowledge, attitudes and practices on IYCF}

In terms of IYCF practices in both case and control households, majority of the children were ever breastfed (98\%); breastfed immediately or within 30 minutes after delivery $(70 \%)$; and given colostrum ( $>75 \%)$. Ever exclusive breastfeeding was lower in cases $(82 \%)$ than in control $(95 \%)$. Less than half of the children in both groups were exclusive breastfed less than 6 months old and $55 \%$ were exclusively breastfed greater than or equal to six months old. For the pre-lacteal feeds, $24 \%$ were given pre-lacteal food among cases while only $18 \%$ in controls. For complementary feeding practices, $11 \%$ of mothers started giving complementary food at six months. Weaning started earlier in control groups while more children were already coffee drinkers in case group (70\%).

Generally, knowledge of mothers regarding infant and young child feeding were remarkably more sufficient among controls compared to cases. The highest score among mothers in the control group came from the statement that as the child's age increases the number of feeding times should also be increased; while the lowest came from the statement that an infant should be breastfed at least 8 times per day. Mothers' attitudes towards ideal nutrition-related practices on IYCF were more positive among controls compared to cases. More mothers in cases claimed that it is difficult to continue breastfeeding beyond 6 months and to breastfeed on demand. There were more mothers in the case group who were not confident to breastfeed while there were more mothers who were not confident to give complementary food in the control group (Table 1).

Factors associated with stunting among the 24-35 months old indigenous children in Pinukpuk, Kalinga

Odds ratio estimation revealed a strong association of stunting with child risk factors including low birth weight, incomplete immunization, and no food supplement intake since birth (Table 2). The odds of getting stunted was 3.5 times $(\mathrm{OR}=3.5 ; 95 \% \mathrm{CI}: 1.57-7.71)$ higher among low-birth-weight children than those children with normal weight at birth. In related studies, children perceived to be very small or small at birth were more likely to be stunted than those perceived to be large at birth (Chirande et al. 2015; Semali et al. 2015). Also, low birth weight infants with IUGR have poor growth and neurodevelopmental outcomes (Sharma et al. 2015). This might be due to maternal nutrition and antenatal care during pregnancy. 


\section{Factors affecting stunting among Kalinga children}

Table 1. Maternal knowledge and attitude on infant and young child feeding in both case and control household

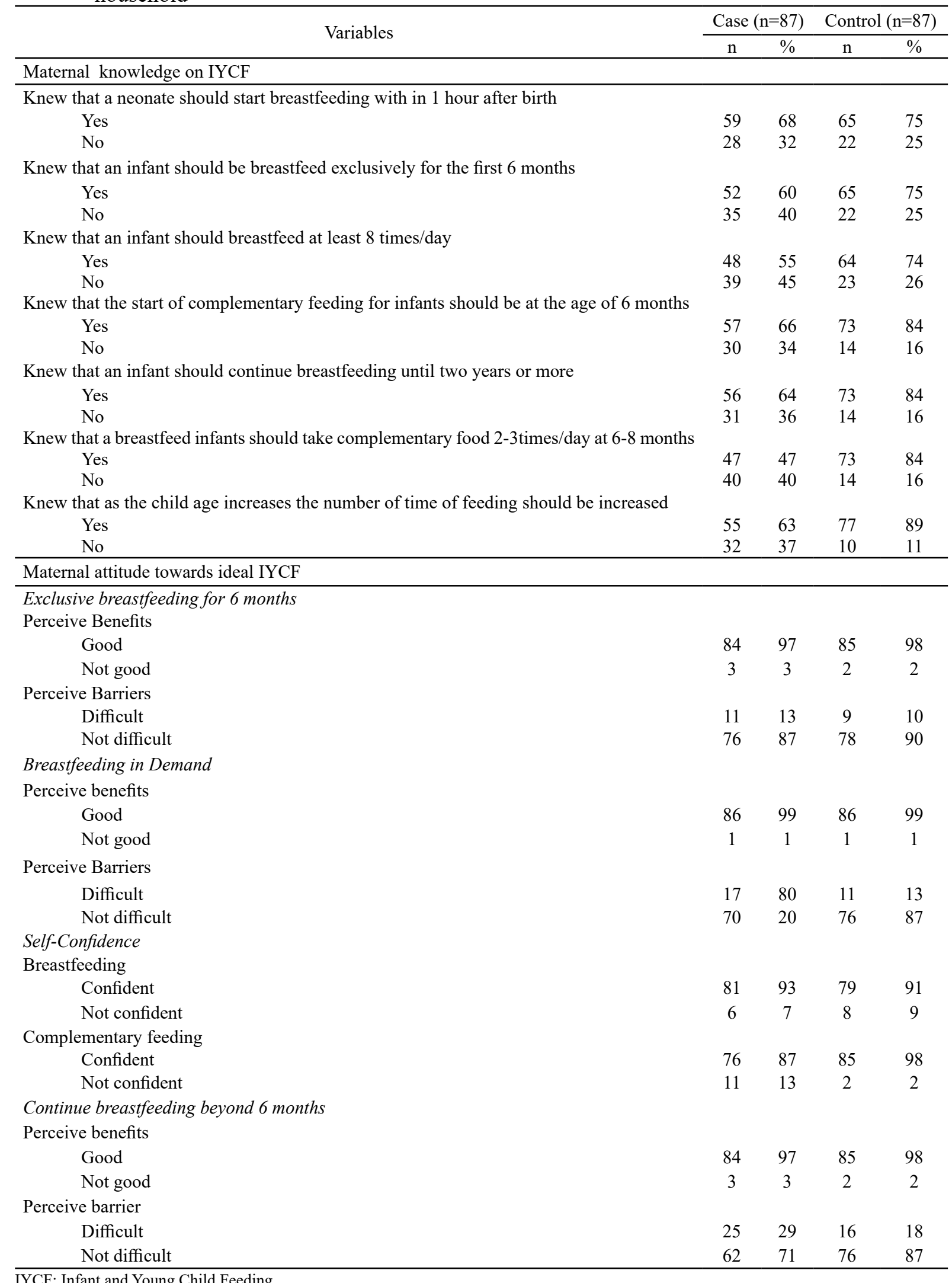

IYCF: Infant and Young Child Feeding 
Piniliw et al.

Table 2. Factors associated with stunting among Kalinga children

\begin{tabular}{lcc}
\hline \multicolumn{1}{c}{ Variables } & OR & $95 \%$ CI \\
\hline Child factors & 3.5 & $1.57-7.71^{* *}$ \\
$\quad$ Low birth weight & 0.2 & $0.07-0.67^{* *}$ \\
$\quad$ Ever exclusively breastfed within the 1st 6 months & 3.2 & $1.27-8.05^{* *}$ \\
$\quad$ Child has not taken supplements since birth & 4.9 & $1.35-17.94^{* *}$ \\
$\quad$ Incomplete immunization & & \\
Parental factors & 2.6 & $1.39-4.94^{* *}$ \\
$\quad$ Full term number of prenatal check-up less than 4 times & 4.7 & $1.49-14.63^{* *}$ \\
$\quad$ Height of father below 5ft & 2.4 & $1.28-4.60^{* *}$ \\
Mother's educational attainment below secondary level & 5.3 & $2.16-12.90^{* *}$ \\
$\quad$ Father's educational attainment below secondary level & & \\
Households factors & 0.5 & $0.29-0.99^{*}$ \\
$\quad$ Nuclear/single family & 0.6 & $0.24-0.87^{* *}$ \\
Household members greater than five & & \\
Cultural factors & & \\
Nutritional beliefs and restrictions & 0.6 & $0.28-1.37$ \\
Have food restriction for pregnant woman & 2.0 & $1.11-3.77^{* *}$ \\
Have food restriction for lactating woman & 0.5 & $0.09-2.74$ \\
Have food restriction for young children & &
\end{tabular}

Children who did not receive the required complete immunization were 4.9 times $(\mathrm{OR}=4.9$; 95\% CI:1.35-17.94) more likely to develop stunting than their counterparts. Similar findings were observed in Southern Ethiopia in which children who did not receive any vaccine were 6.4 times more likely to be under-nourished as compared to those who were completely vaccinated (Batiro et al. 2017). This was probably because the unvaccinated or incompletely vaccinated children were more prone to infectious diseases like pneumonia, diarrhea, and measles, which might have exposed them to undernutrition and growth retardation. Children who never had food supplement intake since birth were 3.2 times $(\mathrm{OR}=3.2 ; 95 \%$ CI:1.27-8.05) more likely to be stunted than children who had taken food supplements since birth. According to the European Food Safety Authority (nd), food supplement is defined as concentrated sources of nutrients or other substances with a nutritional effect that are marketed in dose form. Sufficient food intake and adequate supply of calories, vitamins and minerals are essential for growth and development and the majority of malnourished children fail to achieve their full genetic body growth both linear and ponderal due to the lack of such intake. In this study, micronutrient supplements are from government programs in the form of vitamin A capsules, ferrous sulfate syrup or capsules, and iodine in liquid form, and commercially bought supplements often prescribed by physician to treat or prevent a micronutrient deficiency in young children.

The present study also showed that parental risk factors were significantly associated with stunting like full-term total number of maternal prenatal check-ups less than four times, height of father below $5 \mathrm{ft}$, and mother and father's educational attainment below secondary level. Children of mothers who had less than four times prenatal check-up until delivery were 2.6 times (OR=2.6; 95\% CI:1.39-4.94) more likely to be stunted than their counterparts. A similar study showed that a child of mother who had fewer than four government antenatal care visits during pregnancy was more likely to be malnourished (Hamel et al. 2015). Other authors have also found a positive association between antenatal care services and improved birth outcomes (Kunt $\&$ Volmer 2017). Antenatal visits are indicators of contact with health services and health-seeking behavior which may be associated with better care and feeding practices for young children. Children of father whose height is below $5 \mathrm{ft}$ were 4.7 times (OR=4.7; 95\% CI:1.49-14.63) more likely to develop stunting than children of father whose height is greater than $5 \mathrm{ft}$. Parental height 


\section{Factors affecting stunting among Kalinga children}

influences the offspring's linear growth. Child's linear growth is not only influenced by nutritional status during growth phase but is also affected by genetics (Martorell et al. 2010; Prentice et al. 2013). Thus, a shorter parent is more likely to have shorter children. Children of mothers $(\mathrm{OR}=$ 2.4; 95\% CI:1.28-4.60) and fathers $(\mathrm{OR}=5.3$; 95\% CI:2.16-12.90) with educational attainment below secondary school were more likely to develop stunting than children of parents who attained above secondary education. This finding is similar to other studies conducted in different countries (Biswas \& Bose 2010; Jesmin et al. 2011; Mayhar et al. 2010; Maulundyani et al. 2012). Parental education is associated with improved child-care practices related to health and nutrition and better ability to access and benefit from intervention (Black et al. 2013). Educated mothers have better resource allocation and understanding of nutrition information than the less educated. Household risk factors were also found significantly associated with stunting like type of household and household size (Table 2). In this study, it was found that children living in a nuclear household (OR=0.5; 95\% CI:0.29-0.99) were significantly less likely to develop stunting than children living in an extended household. This finding is consistent with the study conducted in South Africa where stunted children are common with large household members (Mayhar et al. 2010). Association of large number of household members might be due to resource depletion and decrements of food availability and more competition for available food.

The study also demonstrated that cultural risk factors like nutritional beliefs and restrictions for lactating mothers were shown to have statistically significant association with stunting. Children of mothers who believed and practiced cultural nutritional beliefs and restrictions during lactating period were 2.0 times $(\mathrm{OR}=2.0 ; 95 \% \mathrm{CI}: 1.11-3.78)$ more likely to be stunted compared to children of mothers with no nutritional restrictions while lactating (Table 2 ). This might be because food restriction might limit nutritional intake which could contribute to lactation difficulty or failure.

Maternal infant and young child feeding practices found to be statistically and significantly associated with stunting were giving of at least 1 cup or more of coffee to young children, ever exclusively breastfed in the first six months of life and weaning at age greater than 12 months. In this study, mothers who gave their child at least 1 cup or more of coffee a day made their children 2.6 times $(\mathrm{OR}=2.6$; 95\% CI:1.41-4.91) more likely to develop stunting than children of mothers who did not give coffee to their young children. (Table 3) In related studies, caffeinecontaining beverage such as coffee can inhibit calcium absorption and contributes to calcium excretion leading to poor bone growth due to inadequate calcium supply (NIH 2021).

In this study, children who were ever exclusively breastfed in the first six months of their life were significantly less likely to develop stunting as compared to non-ever exclusively breastfed $(\mathrm{OR}=0.2 ; 95 \%$ CI:0.07-0.67). Breast milk is the best food for infants. It provides a unique nutrient composition needed for cell function and growth. Exclusive breastfeeding up to six months of age helps in the attainment of child growth and development and visual acuity (Pem 2015). On the contrary, a study conducted in Libya and Nepal showed that infants exclusively breastfed for either less than six months or more than eight months were more likely to be stunted (Taguri et al. 2008). Ideally, breastfeeding should be exclusively practiced during the first six months of life. In this study, children who were weaned at the age greater than 12 months were less likely to be stunted as compared to children weaned at the age below 12 months $(\mathrm{OR}=0.5$; 95\% CI:0.26-0.95). Yet, other studies showed that children breastfed for more than 12 months were significantly more likely to be stunted than those breastfed up to 12 months (Akombi et al. 2017; Tiwari et al. 2014). This might be a result of cultural influences, quality of complementary feed, availability of food in the household, and maternal knowledge.

Maternal knowledge of IYCF is an important factor for successful child feeding. In this study, maternal knowledge on IYCF was found statistically significant risk factors associated with stunting. Table 3 shows that children of mothers who had insufficient knowledge on the duration of exclusive breastfeeding, proper frequency of breastfeeding, and proper way of administering breastfeeding, right age of child to receive complementary food, proper amount of complementary food per day depending on the age of the child, continue breastfeeding until two years or more and benefit 
Piniliw et al.

Table 3. Maternal infant and young child feeding KAP associated with stunting

\begin{tabular}{|c|c|c|}
\hline Variables & OR & $95 \% \mathrm{CI}$ \\
\hline \multicolumn{3}{|l|}{ Maternal practices on IYCF } \\
\hline Ever exclusively breastfeed within the $1^{\text {st }} 6$ months & 0.2 & $0.07-0.67^{* *}$ \\
\hline Age of weaning $\geq 12$ months & 0.5 & $0.26-0.95^{*}$ \\
\hline Child drinks one or more than a cup of coffee per day & 2.6 & $1.41-4.91^{* *}$ \\
\hline \multicolumn{3}{|l|}{ Maternal knowledge on IYCF } \\
\hline Did not know that an infant should be breastfed exclusively for the first 6 months & 2.0 & $1.04-3.79^{*}$ \\
\hline Did not know that an infant should breastfeed at least 8 times/day & 2.3 & $1.20-4.27^{* *}$ \\
\hline $\begin{array}{l}\text { Did not know that an infant should finish one breastmilk before switching to } \\
\text { another breast }\end{array}$ & 2.5 & $1.27-4.99^{* *}$ \\
\hline $\begin{array}{l}\text { Did not know that the start of complementary feeding for infants should } \\
\text { be at the age of } 6 \text { months }\end{array}$ & 2.7 & $1.33-5.65^{* *}$ \\
\hline $\begin{array}{l}\text { Did not know that an infant should continue breastfeeding until two years } \\
\text { or older }\end{array}$ & 2.9 & $1.40-5.93^{* *}$ \\
\hline $\begin{array}{l}\text { Did not know that a breastfed infant should take complementary food } 2-3 \\
\text { times/day at 6-8 months }\end{array}$ & 4.4 & $2.18-9.03^{* *}$ \\
\hline $\begin{array}{l}\text { Did not know that as the child's age increases the number of feeding times } \\
\text { should also be increased }\end{array}$ & 4.5 & $2.03-9.87^{* *}$ \\
\hline $\begin{array}{l}\text { Did not know that exclusive breastfeeding during the first } 6 \text { months is } \\
\text { beneficial to lactating mothers }\end{array}$ & 2.8 & $1.27-6.10^{* *}$ \\
\hline \multicolumn{3}{|l|}{ Maternal attitudes towards ideal } \\
\hline Not confident preparing complementary food & 6.0 & $1.32-28.64^{*}$ \\
\hline Positive attitudes towards perceived benefits of frequent feeding & 0.1 & $0.01-0.94^{*}$ \\
\hline Difficult to feed child frequently & 2.0 & $0.76-5.31$ \\
\hline
\end{tabular}

${ }^{*} \mathrm{p}<0.05 ;{ }^{* *} \mathrm{p}<0.001$; IYCF: Infant and Young Child Feeding; KAP: Knowledge, Attitude, and Practices

of exclusive breastfeeding for six months to lactating mothers were significantly more likely to be stunted as compared to their counterpart. Similar study was observed in Bangladesh that showed significant association between nutritional status and maternal child care. Unadjusted mean of height-for-age Z-scores of children born to mothers having high level of maternal child care knowledge were significantly higher than those children of mothers who had lower knowledge levels in child care practices (Saaka 2014). Knowledge of mothers on IYCF recommendations has statistically significant association with their IYCF practices. Mothers who had insufficient knowledge of IYCF recommendation were more likely to have inappropriate feeding practices (Demilew 2017).

Table 3 also shows that maternal attitudes towards ideal child feeding and nutrition-related practices were found to be significant risk factors for stunting. Children of mothers who were not confident that they prepared complementary food for their child correctly were 6.1 times more likely to be stunted as compared to their counterparts. Mothers who had positive attitude towards the benefits of frequent child feeding made their children less likely to develop stunting. Positive attitude towards infant feeding is an important component in child nutritional health.

\section{CONCLUSION}

Stunting was found to be a result of multiple factors such as low birth weight, incomplete immunization, no food supplement intake, household type and size, and maternal and infant and young child practices particularly exclusive breastfeeding, and maternal knowledge. The study implied that preventing stunting requires multi-disciplinary approach, the study suggests that public health intervention programmer should focus on these risk factors to reduce or 
alleviate stunting. Maternal knowledge on IYCF plays an important role on the prevention of stunting. Mothers/caregivers should be educated on the importance of exclusive breastfeeding with its proper mechanics, methods of complementary feeding, and maternal care and nutrition during pregnancy and lactation. Programs or advocacies promoting proper nutrition, breastfeeding, multiple micronutrient supplementation, immunization, periodic growth monitoring, as well as knowledge of mothers on their child's nutritional status should be strengthened to address the risk factors of stunting.

\section{ACKNOWLEDGEMENT}

The researcher would like to extend its gratitude and appreciation to National Commission on Indigenous People which permitted to conduct the study and the Accelerated Science and Technology Human Resource Development Program-National Science Consortium (ASTHRDP-NSC) under the Department of Science and Technology (DOST) which has provided funding for this research.

\section{AUTHOR DISCLOSURES}

The authors have no conflict of interest.

\section{REFERENCES}

Adair LS, Fall CH, Osmond C, Stein AD, Martorell R, Ramirez-Zea M, Sachdev HS, Dahly DL, Bas I, Norris SA et al. 2013. Associations of linear growth and relative weight gain during early life with adult health and human capital in countries of low and middle income: Findings from five birth cohort studies. The Lancet 382(9891):525-534. https:// doi.org/10.1016/S0140-6736(13)60103-8

Akombi BJ, Agho KE, Hall JJ, Merom D, AstellBurt T, Renzaho AMN. 2017. Stunting and severe stunting among children under-5 years in Nigeria: A multilevel analysis. BMC Pediatrics 17(1):1-16. https://doi. org/10.1186/s12887-016-0770-Z

Batiro B, Demissie T, Halala Y, Anjulo AA. 2017. Determinants of stunting among children aged 6-59 months at Kindo Didaye woreda, Wolaita Zone, Southern Ethiopia:
Unmatched case control study. Plos One 12(12):e0189106. https://doi.org/10.1371/ journal.pone. 0189106

Biswas S, Bose K. 2010. Sex differences in the effect of birth order and parents' educational status on stunting: A study on Bengalee preschool children from eastern India. Homo 61(4):271-276. https://doi. org/10.1016/j.jchb.2010.03.001

Black RE, Victora CG, Walker SP, Bhutta ZA, Christian P, De Onis M, Ezzati M, Grantham-McGregor S, Katz J, Martorell $\mathrm{R}$, et al. 2013. Maternal and child undernutrition and overweight in lowincome and middle-income countries. The Lancet 382(9890):427-451. https://doi. org/10.1016/S0140-6736(13)60937-X

Chirande L, Charwe D, Mbwana H, Victor R, Kimboka S, Issaka AI, Baines SK, Dibley MJ, Agho KE. 2015. Determinants of stunting and severe stunting among underfives in Tanzania: Evidence from the 2010 cross-sectional household survey. BMC Pediatrics 15(1):1-13. https://doi. org/10.1186/s12887-015-0482-9

Demilew YM. 2017. Factors associated with mothers' knowledge on infant and young child feeding recommendation in slum areas of Bahir Dar City, Ethiopia: Cross sectional study. BMC Research Notes 10(1):1-7. https://doi.org/10.1186/s13104017-2510-3

El Taguri A, Betilmal I, Mahmud SM, Ahmed AM, Goulet O, Galan P, Hercberg S. 2009. Risk factors for stunting among under-fives in Libya. Public Health Nutr 12(8):1141-1149. https://doi.org/10.1017/ S1368980008003716

[EFSA] European Food Safety Authority. n.d. Food Supplements. https://www. efsa.europa.eu/en/topics/topic/foodsupplements [Accessed 23rd May 2021].

[FNRI-DOST] Food and Nutrition Research Institute. 2015. 2015 Updating of the Nutrition Status of the Filipino Children and other Population Group: Anthropometric Survey. Department of Science and Technology. Taguig City, Metro Manila. Philippines.

Habimana S, Biracyaza E. 2019. Risk factors of stunting among children under 5 years of age in the eastern and western provinces of 
Rwanda: Analysis of Rwanda demographic and health survey 2014/2015. Pediatric Health Med Ther 10:115-130. https://doi. org/10.2147/PHMT.S222198

Hamel C, Enne J, Omer K, Ayara n, Yarima Y, Cockrocft A, Andersson N. 2015. Childhood malnutrition is associated with maternal care during pregnancy and childbirth: A cross sectional study in Bauchi and Cross River State Nigeria. J Public Health Res 4(1):408 https://doi. org/10.4081/jphr.2015.408

Horta BL, Santos RV, Welch JR, Cardoso AM, dos Santos JV, Assis AMO, Lira PC, Coimbra Jr CEA. 2013. Nutritional status of indigenous children: Findings from the first national survey of Indigenous people's health and nutrition in Brazil. Int J Equity Health 12(1):1-13. https://doi. org/10.1186/1475-9276-12-23

Jesmin A, Yamamoto SS, Malik AA, Haque MA. 2011. Prevalence and determinants of chronic malnutrition among preschool children: a cross-sectional study in Dhaka City, Bangladesh. Journal of Health Popul Nutr 29(5):494-499. https://doi. org/10.3329/jhpn.v29i5.8903

Kuhnt J, Vollmer S 2017. Antenatal care services and its implications for vital and health outcomes of children: Evidence from 193 surveys in 69 low-income and middle-income countries. BMJ Open 7(11): p.e017122. https://doi.org/10.1136/ bmjopen-2017-017122

Martorell R, Horta BL, Adair LS, Stein AD, Richer L, Fall CHD, Bhargava SK, Biswas SKD, Perez L, Barris FC, et al. 2010. Weight gain in the first two years of life is an important predictor of schooling outcome in pooled analysis from five births cohorts from low- and middle-income countries. J Nutr 140(2):348-354. https:// doi.org/10.3945/jn.109.112300

Mahyar A, Ayazi P, Fallahi M, Haji SJT, Farkhondehmehr B, Javadi A, Kalantari Z. 2010. Prevalence of underweight, stunting and wasting among children in Qazvin, Iran. Iranian J Pediatr Soc 2(1):37-43. https://doi.org/10.1016/j. pediatrneurol.2010.05.024

Mauludyani AVR, Fahmida U, Santika O. 2012. Undernutrition prevalence among children under two years old in Indonesia during economic crisis and its related factors. $\mathrm{J}$
Gizi Pangan 7(3):169-174. https:// doi.org/10.25182/jgp.2012.7.3.169-174

[NIH] National Institute of Health. 2021. Fact sheet for health professionals. https:// ods.od.nih.gov/factsheets/calciumHealthProfessional/\#en16 [Accessed 29th June 2021].

Pem D. 2015. Factors affecting early childhood growth and development: Golden 1000 days.Adv Practice Nurs 1(101):2573-0347. https://10.4172/25730347.1000101

Prentice AM, Ward KA, Goldberg GR, Jarjou LM, Moore SE, Fulford AJ, Prentice A. 2013. Critical windows for nutritional interventions against stunting. Am J Clin.Nutr 97(5):911-918. https://doi. org/10.3945/ajen.112.052332

Saaka M. 2014. Relationship between mothers' nutritional knowledge in childcare practices and the growth of children living in impoverished rural communities. J Helath Popul Nutr 32(2):237-248.

Save The Children. 2012. A Life Free From Hunger. Tackling Child Malnutrition. London (UK): SaveThe Children UK.

Semali IA, Tengia-Kessy A, Mmbaga EJ, Leyna G. 2015. Prevalence and determinants of stunting in under-five children in central Tanzania: Remaining threats to achieving Millennium Development Goal 4. BMC Public Health 15(1):1-6. https://doi. org/10.1186/s12889-015-2507-6

Sharma D, Shastri S, Sharma P. 2016. Intrauterine growth restriction: Antenatal and postnatal aspects. Clinical Medicine Insights: Pediatrics 10: pp.CMPed-S40070. https:// doi.org/10.4137/CMPed.S40070

Tanner S, Leonard WR, Reyes-García V, TAPS Bolivia Study Team. 2014. The consequences of linear growth stunting: Influence on body composition among youth in the Bolivian Amazon. Am J Phys Anthropol 153(1):92-102. https://doi. org/10.1002/ajpa.22413

Tiwari R, Ausman LM, Agho KE. 2014. Determinants of stunting and severe stunting among under-fives: Evidence from the 2011 Nepal demographic and health survey. BMC Pediatr 14(1):1-15. https://doi.org/10.1186/1471-2431-14-239

[UNICEF] United Nations Children's Fund. 2015. Annual report 2015. UNICEF. https://www.unicef.org/media/50046/file/ UNICEF_Annual_Report_2015_ENG.pdf [Accessed 20th January 2016]. 